\title{
Spatiotemporal Distribution and Alpine Behavior of Short Chain Chlorinated Paraffins in Air at Shergyla Mountain and Lhasa on the Tibetan Plateau of China
}

\author{
Jing Wu, ${ }^{\dagger, \dagger}$ Wei Gao, ${ }^{\dagger, \dagger}$ Yong Liang, ${ }^{\S}$ Jianjie Fu, ${ }^{\dagger}$ Yan Gao, ${ }^{\dagger}$ Yawei Wang, ${ }^{*}, \dagger, \downarrow, \S \odot$ and Guibin Jiang ${ }^{\dagger}$ \\ ${ }^{\dagger}$ State Key Laboratory of Environmental Chemistry and Ecotoxicology, Research Center for Eco-Environmental Sciences, Chinese \\ Academy of Sciences, Beijing 100085, China \\ ${ }^{\ddagger}$ University of Chinese Academy of Sciences, Beijing 100049, China \\ ${ }^{\S}$ Institute of Environment and Health, Jianghan University, Wuhan 430056, China
}

Supporting Information

\begin{abstract}
Pristine high-altitude mountains are ideal areas for studying the potential mechanism behind the long-range transport and environmental behavior of persistent organic pollutants in remote areas. Short chain chlorinated paraffins (SCCPs) are the most complex halogenated contaminants in the environment, and have attracted extensive worldwide interest in recent years. In this study, the spatiotemporal concentrations and distributions of SCCPs in air collected from Shergyla Mountain (located in the southeast of the Tibetan Plateau) and Lhasa were investigated during 20122015. Generally, the total SCCP levels at Shergyla Mountain and Lhasa were between 130 and $1300 \mathrm{pg} / \mathrm{m}^{3}$ and $1100-$ $14440 \mathrm{pg} / \mathrm{m}^{3}$, respectively. $\mathrm{C}_{10}$ and $\mathrm{C}_{11}$ components were the

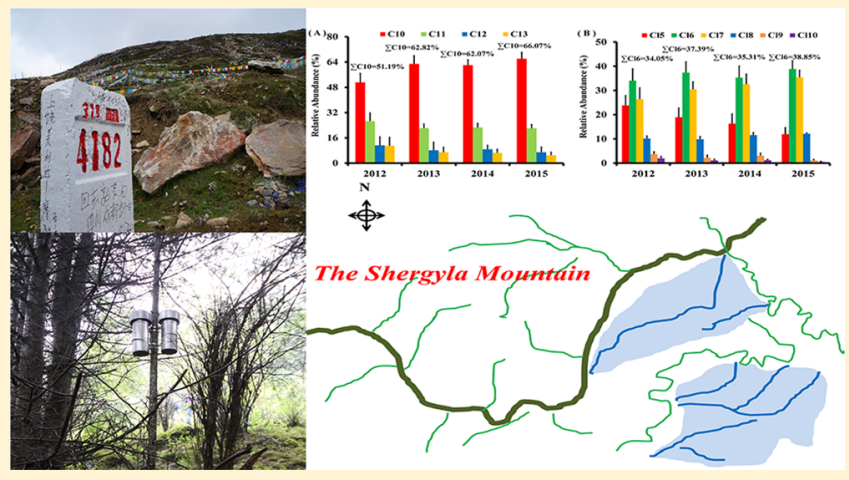
most abundant homologue groups, indicating that lighter SCCP homologue groups are capable of relatively long-range atmospheric transport. Relatively high but insignificant atmospheric SCCP concentrations at Shergyla Mountain area and Lhasa were observed from 2013 to 2015 compared with 2012. At Shergyla Mountain, SCCP concentrations on the eastern and western slopes increased with altitude, implying that "mountain cold-trapping" might occur for SCCPs. A back-trajectory model showed that SCCP sources at Shergyla Mountain and Lhasa were primarily influenced by the tropical monsoon from Southwest and South Asia.
\end{abstract}

\section{INTRODUCTION}

Chlorinated paraffins (CPs), a complex class of polychlorinated $n$-alkanes, are generally used as additives in industrial applications, such as metal-working fluids, sealants, paints, and leather treatment chemicals. ${ }^{1} \mathrm{CPs}$, including short chain CPs $\left(\mathrm{C}_{10-13}\right.$, SCCPs $)$, medium chain $\mathrm{CPs}\left(\mathrm{C}_{14-17}, \mathrm{MCCPs}\right)$ and long chain CPs $\left(\mathrm{C}_{18-30}\right.$, LCCPs $)$ are classified based on the carbon chain length. ${ }^{2}$ SCCPs have attracted particular attention owing to their long-range transport, ${ }^{3}$ persistence in the environment, ${ }^{4}$ high bioaccumulation potential, ${ }^{5}$ and toxicity to aquatic organsims. ${ }^{6,7}$ SCCPs were listed under the Stockholm Convention as a persistent organic pollutant (POP) candidate in $2006^{8}$ and the Conference of Parties decided to put SCCPs into Annex A in 2017.

Long range atmospheric transport (LRAT) is the main mechanism for transporting POPs to polar regions and high altitude regions. On the basis of previous work, POPs such as hexachlorobenzene (HCBs) and hexachlorocyclohexanes ( $\mathrm{HCHs})$ are assumed to migrate to higher latitudes and be deposited in ecosystems by global fractionation and condensation, which is termed the "polar cold-trapping" effects."
Remote high-altitude mountain regions with low temperatures and deep snow accumulation have similar environments as polar areas. In these polar-like environments, the distillation and cold condensation effects can easily occur, and are known as "mountain cold-trapping". Similar to other POPs, SCCPs released into the environment ${ }^{11-13}$ can also reach remote or polar areas since they have similar physical and chemical properties with other POPs. However, data regarding the environmental fate of SCCPs are limited, especially concerning the potential effects in remote areas; this is primarily due to the complexity of SCCP compositions, analytical difficulties, and difficulties obtaining samples. ${ }^{14-18}$ Only limited works for the environmental behavior of SCCPs in remote areas such as Norwegian Svalbard, Bear Island, the Arctic, and Antarctica have been reported. ${ }^{19-22}$ In China, the atmospheric levels of

Received: July 7, 2017

Revised: September 4, 2017

Accepted: September 12, 2017

Published: September 12, 2017 


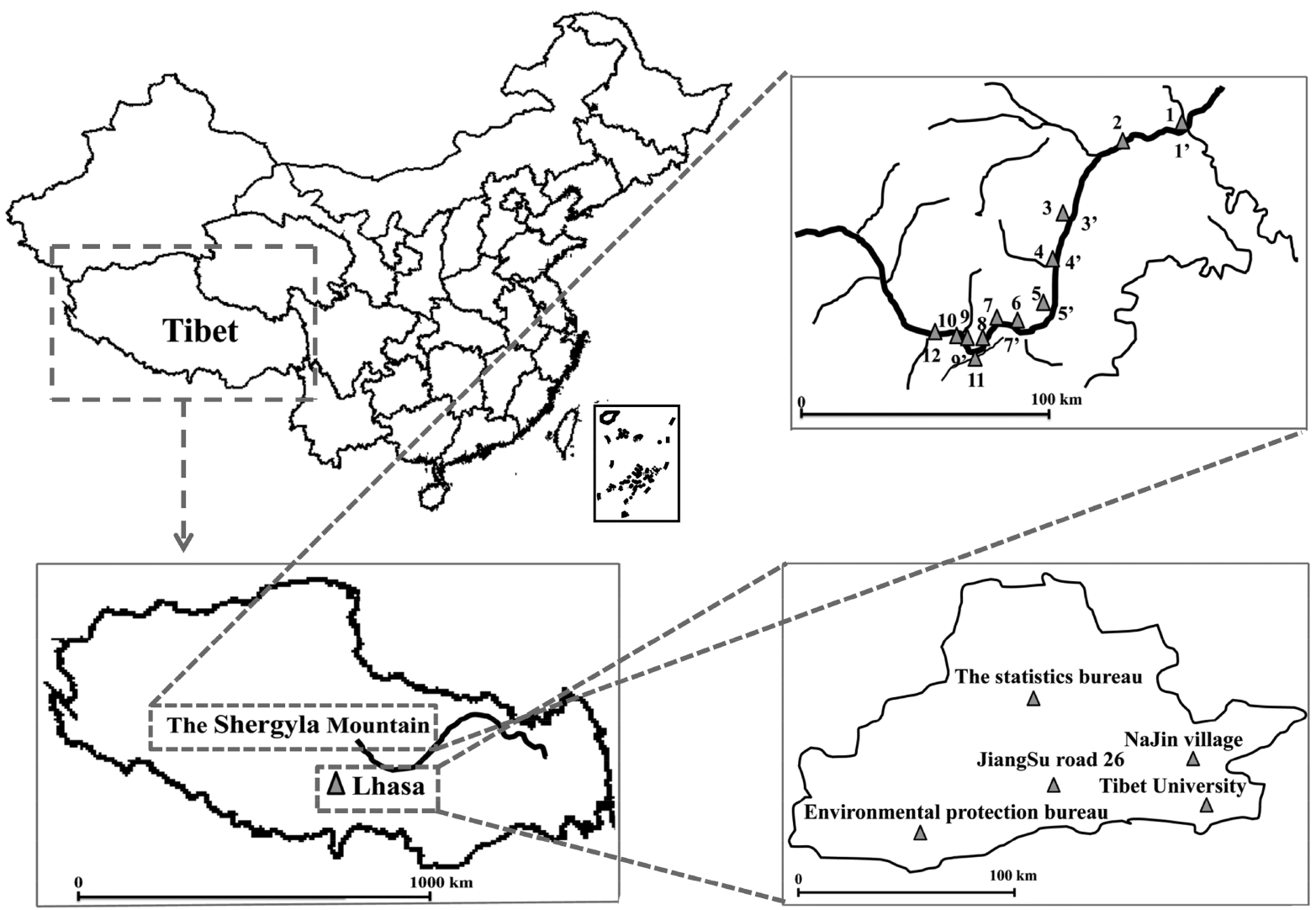

Figure 1. Sampling sites at Shergyla Mountain, southeast of the Tibetan Plateau, and Lhasa. At Shergyla Mountain, sampling site 6 was the top of mountain, sites 1-5 were on the eastern slopes and sites 7-12 were on the western slopes. Sampling sites 1-10 were inside the forest, while sites $1^{\prime}$, $3^{\prime}, 4^{\prime}, 5^{\prime}, 6,7^{\prime}, 9^{\prime}, 11^{\prime}$, and $12^{\prime}$ were outside the forest.

SCCPs have been reported but scarcely any reports about the remote regions could be found. ${ }^{23,24}$

The Tibetan Plateau lies to the north of the Himalayas. As the "the third pole", the altitude of the Tibetan Plateau is high and the weather is variable owing to the complex climate and abundant vegetation coverage. The sparse human population and scarce industrial activities mean that POPs have few local sources in this high altitude mountain region. Therefore, atmospheric transport is regarded as the primary external source for POPs. Shergyla Mountain, located in the southeast of the Tibetan Plateau, is a major forest terrain on the Tibetan Plateau. The effects of large amounts of moisture passing through the Yarlung Tsangpo Valley and the presence of large mountains cause the eastern and western slopes of Shergyla Mountain to exhibit variable climates, such as high rainfall on the eastern slopes (approximately $1000 \mathrm{~mm}$ per year) and variable wind direction. Shergyla Mountain, with its steep gradients and upward prevailing wind, is the ideal place to study the mountain cold-trapping effect for POPs.

In this work, the concentrations and composition profiles of SCCPs in air were investigated along elevation gradients at Shergyla Mountain and Lhasa for 2012 to 2015 using XADbased passive air samplers (PAS). The objectives of this work were to provide spatiotemporal SCCP concentration trends and to examine SCCP composition profiles in this remote mountain area in order to reveal the potential sources and longrange atmospheric transport of SCCPs. As the mountain coldtrapping effect for SCCPs in the atmosphere of the Tibetan Plateau has not yet been investigated, we attempted to reveal the underlying mechanism, considering the trend with altitude for SCCPs at Shergyla Mountain. The SCCP concentrations and composition profiles on the eastern and western slopes of Shergyla Mountain were also compared to study the possible transport mechanisms for SCCPs in a high-altitude area given various environmental parameters.

\section{EXPERIMENTAL SECTION}

Sampling. As they possess a high capacity for accumulating POPs throughout year-round monitoring, XAD resin PAS can be used for long-term air monitoring of POPs. ${ }^{26-28}$ To evaluate the possibility of XAD resin PAS for monitoring SCCPs in air, the sorption curve of XAD for SCCPs was investigated for Beijing air for a period of 60 days (Figure S1, Supporting Information, SI). The concentrations of SCCPs sorbed on the PAS linearly increased during the sampling period in terms of both the total SCCP concentrations and the individual homologue group concentrations. After 55 days of passive air sampling in Beijing, SCCP concentrations exceeded the highest concentrations observed in the air collected from Tibet in this work, which implied that SCCPs did not reach the maximum sorption capacity of the PAS. Therefore, XAD resin PAS were considered appropriate for use in the air sampling campaign in Tibet. In this work, the sampling campaign was carried out at Lhasa and Shergyla Mountain, in the southeastern Tibetan Plateau from July 2012 to July 2015. At Lhasa, the five sampling sites (Figure 1) were evenly distributed across the city, and sampling was carried out on rooftops. At Shergyla Mountain, the mountainous sampling sites had steep gradients, and covered a range of altitudes from 1983 to $4553 \mathrm{~m}$ a.s.l. (above sea level). The sampling map is shown in Figure 1. Before use, 

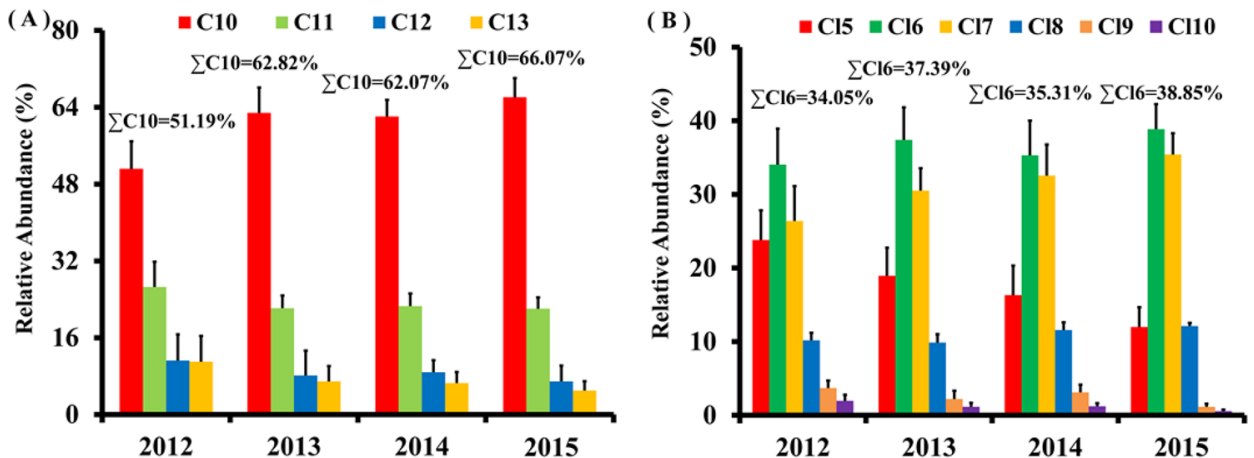

Figure 2. Composition abundance profiles for SCCPs congeners, $C_{10}-C_{13}(A)$ and $C_{5}-C l_{10}$ (B), at Shergyla Mountain from 2012 to 2015.

the $\mathrm{XAD}$ resin was cleaned using methanol, acetone, and dichloromethane (DCM) sequentially, before further cleaning by Soxhlet extraction using DCM. Afterward, the XAD resin was completely dried in a clean desiccator, and a precleaned stainless steel mesh cylinder was then filled with XAD resin. Finally, the XAD-PAS were placed along elevation gradients (the interval between adjacent sampling sites was approximately 200-300 m) at Shergyla Mountain for a sampling period of one year. At Shergyla Mountain, separate sampling sites were located on the eastern and western slopes. To evaluate possible forest filter effects for SCCPs, the sampling campaign also included the forested areas and corresponding areas outside of the forest. In total, 83 air samples were obtained ( $n=20$ for 2012, 21 for 2013, 21 for 2014, 21 for 2015). During the sampling, triplicate XAD resin blanks were prepared.

Sample Pretreatment. Pesticide grade acetone, cyclohexane, $n$-hexane $(n$-Hex), DCM, and toluene were obtained from J. T. Baker (Center Valley PA, U.S.A.). Silica gel (180280 mesh) and Florisil (60-100 mesh) were purchased from Merck (Whitehouse Station, NJ, U.S.A.). Anhydrous sodium sulfate was activated at $660{ }^{\circ} \mathrm{C}$ for $6 \mathrm{~h}$, silica gel at $550{ }^{\circ} \mathrm{C}$ for $12 \mathrm{~h}$, and Florisil at $140{ }^{\circ} \mathrm{C}$ overnight before use. Reference SCCPs (chlorine contents of 51.5\%, 55.5\%, and 63\%) with concentrations of $100 \mathrm{ng} / \mu \mathrm{L}$ in cyclohexane and $\varepsilon-\mathrm{HCH}(100$ $\mathrm{ng} / \mu \mathrm{L}$ solution in $n$-nonane, purity $99 \%)$ were purchased from Dr. Ehrenstorfer $\mathrm{GmbH}$ (Augsburg, Germany). ${ }^{13} \mathrm{C}_{10}$-transchlordane was obtained from Cambridge Isotope Laboratories (Andover, MA, U.S.A.).

Each sample was spiked with $1 \mathrm{ng}$ of ${ }^{13} \mathrm{C}_{10}$-trans-chlordane and extracted by dichloromethane and $n$-hexane (1:1) using Dionex 350 accelerated solvent extraction (ASE) (150 and $1500 \mathrm{psi}$ ). The thermal equilibration time was $10 \mathrm{~min}$, and the static extractions were carried out in three cycles $(8 \mathrm{~min} /$ cycle $)$. After extraction, the extract was cleaned using a multilayered vitreous column that consisted of layers of (from bottom to top) $3 \mathrm{~g}$ of activated Florisil, $2 \mathrm{~g}$ of activated silica gel, $5 \mathrm{~g}$ of acid silica gel $(30 \%, w / w)$, and $4 \mathrm{~g}$ of anhydrous sodium sulfate. More details of the cleanup procedures can be found in our previously published work. ${ }^{29,30}$ Before instrumental analysis, 10 ng of $\varepsilon-\mathrm{HCH}$ was added to the concentrated sample as a recovery internal standard to measure the methodological recovery.

Instrumental Analysis. The instrumental analysis was performed using a 7890A gas chromatograph coupled with a $7000 \mathrm{~A}$ triple quadrupole mass spectrometer in electron capture negative ion mode (Agilent, AC) using the selected ion monitoring (SIM) mode. The injection was performed using a $7683 \mathrm{~B}$ series injector and the samples were injected into a DB-
5MS column (30 m length, $0.25 \mathrm{~mm}$ i.d., $0.25 \mu \mathrm{m}$ film thickness; Agilent, CA) at an injector temperature of $280{ }^{\circ} \mathrm{C}$. Instrumental parameters and the monitored fragmentation ions for the GC-ECNI-LRMS method are described in our previous works. $^{29,30}$ The oven temperature for the chromatographic separation was initially kept at $100{ }^{\circ} \mathrm{C}$ for $1 \mathrm{~min}$. It was then increased from $30{ }^{\circ} \mathrm{C} / \mathrm{min}$ to $160{ }^{\circ} \mathrm{C} / \mathrm{min}$ for $5 \mathrm{~min}$, and later increased to $310^{\circ} \mathrm{C}$ at $30^{\circ} \mathrm{C} / \mathrm{min}$. Thereafter, it was retained at $310{ }^{\circ} \mathrm{C}$ for $22 \mathrm{~min}$. The ion source was set at $200{ }^{\circ} \mathrm{C}$ and the transfer line temperature was set at $280{ }^{\circ} \mathrm{C}$. The target SCCP homologue group patterns $\left(\mathrm{C}_{10}-\mathrm{C}_{13}\right)$ including chlorine numbers from 5 to 10 were monitored under the above conditions. The most and second most abundant isotope ions of $[\mathrm{M}-\mathrm{Cl}]^{-}$for each homologue group were selected for quantitative and qualitative ion measurements. ${ }^{2,15}$

The identification of SCCP homologue groups was carried out as in our previous works. ${ }^{29-31}$ SCCP homologue group patterns were divided into four groups $\left(\mathrm{C}_{10}, \mathrm{C}_{11}, \mathrm{C}_{12}\right.$, and $\left.\mathrm{C}_{13}\right)$ using the high instrumental resolution. The quantification of each sample was conducted, based on our previous work, ${ }^{29-31}$ using four individual injections to avoid the interference of MCCP when quantifying SCCPs, and the quantitation procedure for SCCPs can be found in the SI.

Quality Assurance/Quality Control. All glassware was steeped in deionized water with Decon 90 for at least $6 \mathrm{~h}$ and then washed three times using deionized water to avoid contamination. All glassware was heated at $450{ }^{\circ} \mathrm{C}$ overnight and completely rinsed with $n$-hexane and dichloromethane three times before use. The ASE cells were ultrasonicated in dichloromethane three times and rinsed three times using dichloromethane and $n$-hexane $(1: 1)$ by the ASE instrument at $150{ }^{\circ} \mathrm{C}$ prior to use. The empty cell was cleaned before use by extractions of $15 \mathrm{~min}$ for equilibration followed by three cycles ( $8 \mathrm{~min} /$ cycle). During the extractions, the cell was purged with gaseous nitrogen for $100 \mathrm{~s}$. Spot blank samples and traveling blank samples were extracted to ensure data quality before experiments. In each batch of six samples, one procedural blank sample was included to monitor potential contamination. In general, SCCP levels in the field and laboratory blanks were close to or below the limit of detection (LOD) for total SCCP concentrations. The method detection limit (MDL) is calculated as three times the standard deviation of procedural blanks for all the experimental batches and the MDL value was $40 \mathrm{pg} / \mathrm{m}^{3}$. The recovery of ${ }^{13} \mathrm{C}_{10}$-trans-chlordane for $\mathrm{XAD}$ resin samples was in the range of $85 \%-103 \%$. 

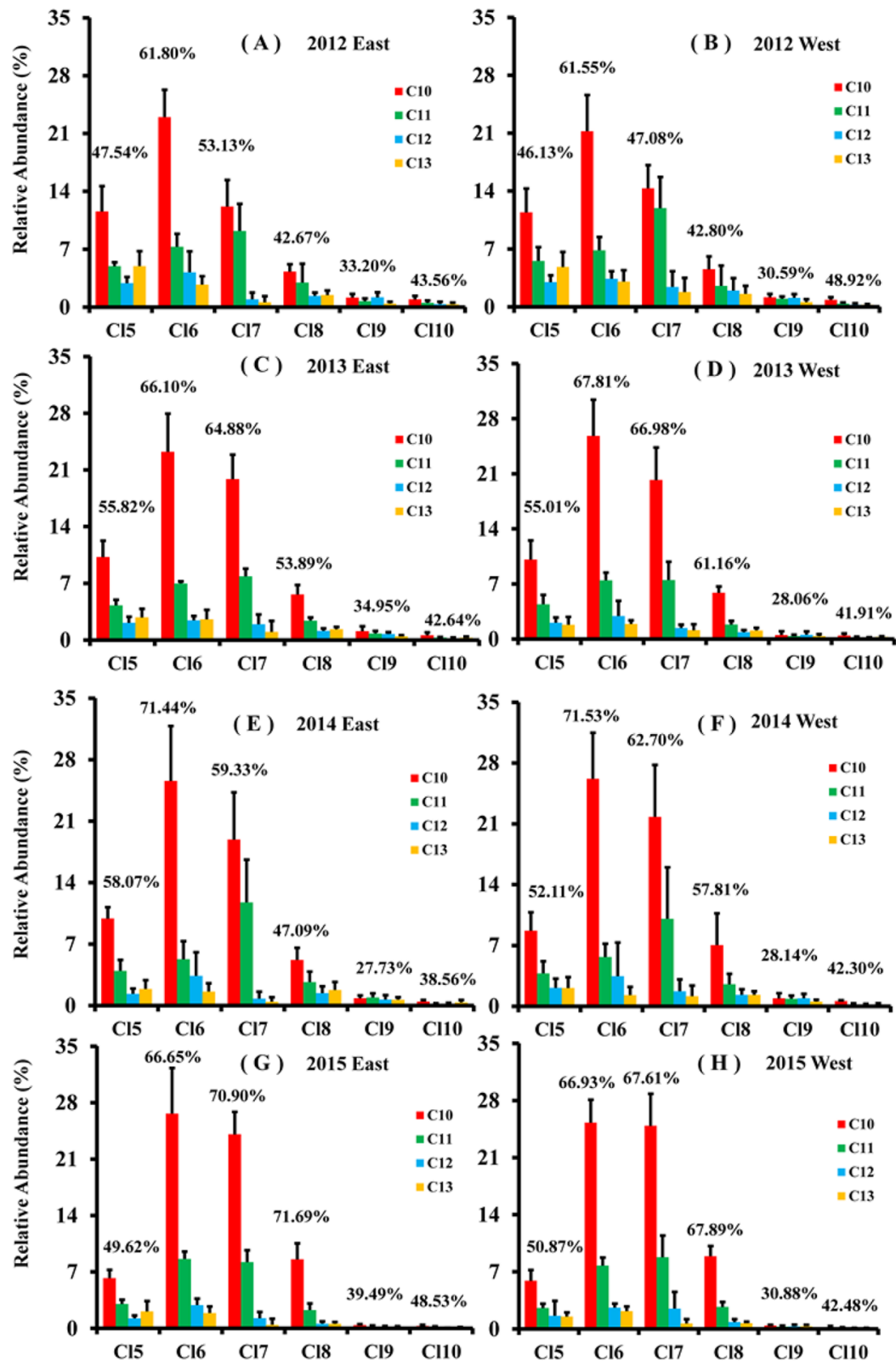

Figure 3. Relative abundance composition profiles of the SCCP homologue groups $\left(\mathrm{Cl}_{5}-\mathrm{Cl}_{10}\right)$ on the eastern and western slopes of Shergyla Mountain from 2012 to 2015 . The percentages represent the composition profiles of SCCP homologue groups with $\mathrm{C}_{10}$.

\section{RESULTS AND DISCUSSION}

Airborne SCCP Concentrations and Homologue Group Patterns at Shergyla Mountain. On the basis of the fact that the sampling sites for this study match those used in our previous work on organochlorine pesticides (OCPs), polychlorinated biphenyls (PCBs), and polybrominated diphenyl ethers (PBDEs), the average specific sampling rate (R) was considered stable at $2.71 \pm 0.77 \mathrm{~m}^{3}$ day $^{-1.27,28,32}$ Correspondingly, the calculated volume of the air samples from Shergyla Mountain and the total SCCP concentrations from 2012 to 2015 are presented in Table S1 (SI). The total SCCP concentrations in the atmosphere at Shergyla Mountain ranged from 132 to $1267 \mathrm{pg} / \mathrm{m}^{3}$, with an average value of $229 \mathrm{pg} / \mathrm{m}^{3}$ in $2012,352 \mathrm{pg} / \mathrm{m}^{3}$ in 2013, $696 \mathrm{pg} / \mathrm{m}^{3}$ in 2014 and $553 \mathrm{pg} / \mathrm{m}^{3}$ in 2015. Generally, the total airborne SCCP concentrations at Shergyla Mountain were approximately 10 times lower than those found in some Asian cities, e.g., in Japan and South
Korea, ${ }^{23}$ and $10-1000$ times lower than those in Beijing. ${ }^{24,25}$ However, the total concentrations were approximately 10 times higher than those found in the Antarctic and Arctic areas. ${ }^{19,21}$

The SCCP homologue group patterns at Shergyla Mountain show that the $\mathrm{C}_{10}$ and $\mathrm{C}_{11}$ homologue groups were the predominant carbon congeners of SCCPs (Figure 2) with average values of $283 \mathrm{pg} / \mathrm{m}^{3}$ for $\mathrm{C}_{10}$ and $104 \mathrm{pg} / \mathrm{m}^{3}$ for $\mathrm{C}_{11}$. The carbon congener profiles of SCCPs were similar to those found in Antarctica, but significantly different from those found in Lancaster (U.K.), where $\mathrm{C}_{12}$ components accounted the majority of SCCPs. ${ }^{20}$ Among the chlorine groups, $\mathrm{Cl}_{6}$ and $\mathrm{Cl}_{7}$ were the dominant airborne groups at Shergyla Mountain (Figure 2, 3), with the concentrations of $167 \mathrm{pg} / \mathrm{m}^{3}$ and 147 $\mathrm{pg} / \mathrm{m}^{3}$, respectively. The SCCP chlorination degree was in the range of $59.4 \%\left(\mathrm{C}_{13} \mathrm{H}_{23} \mathrm{Cl}_{5}\right)$ to $63.5 \%\left(\mathrm{C}_{10} \mathrm{H}_{12} \mathrm{Cl}_{10}\right)$.

The homologue profiles of the airborne SCCPs at Shergyla Mountain were also similar to those found in the air of most 

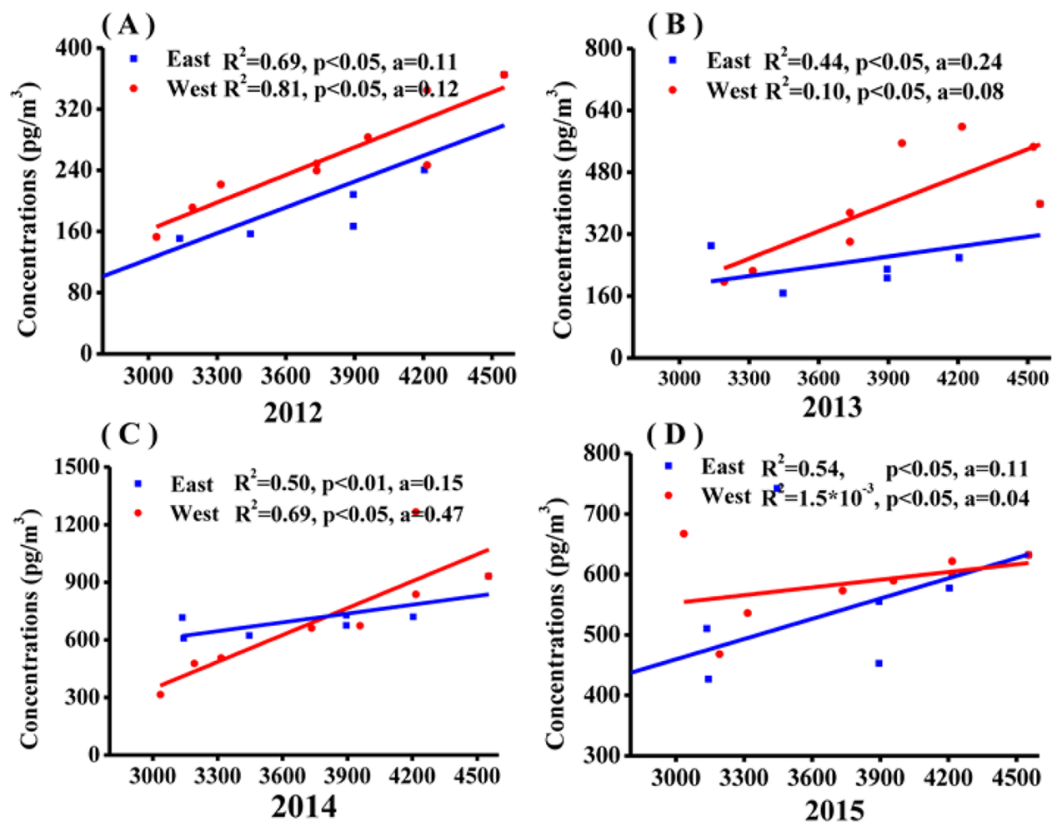

Figure 4. Distribution of SCCPs in air samples versus altitude on the eastern and western slopes from 2012 to 2015 . In the legend, "R" represents the regression coefficient and "a" indicates the regression slope.

urban and rural areas of China in that the $\mathrm{C}_{10}, \mathrm{C}_{11}, \mathrm{Cl}_{6}$, and $\mathrm{Cl}_{7}$ homologue groups were the predominant homologues, which was consistent with the compositions of the three major industrial CP products manufactured in the coastal and central regions of China. ${ }^{24,33,34}$

Spatial Distribution of SCCPs with Elevation at Shergyla Mountain. During the sampling period, the SCCP concentrations on the eastern and western slopes were between 132 to $932 \mathrm{pg} / \mathrm{m}^{3}$ and 153 to $1267 \mathrm{pg} / \mathrm{m}^{3}$, respectively. In general, relatively high airborne SCCP concentrations were found on the western slopes, which is similar to our previous finding on DDTs, HCHs, PBDEs, and HBCDs in the same sampling area. ${ }^{28}$

On both the eastern and western slopes, the SCCP concentrations gradually increased with elevation, but the increasing trend on the western slopes was more obvious. As the elevation increased from $3136 \mathrm{~m}$ a.s.l. to $4553 \mathrm{~m}$ a.s.l., the SCCP concentrations increased by a factor of approximately 1.3-2.9 on the western slopes and 1.5-2.7 on the eastern slopes. This could be due to the mountain cold-trapping effect, which is defined as an increase in POP concentrations corresponding to an increase in the elevation of typical mountain areas, caused by repeating the temperature-driven air surface exchanges. ${ }^{35,36}$ The concentration trends for the concentration of the general chlorination homologue groups on the eastern and western slopes was similar to the carbon homologue group trends. The increasing trends in the total SCCP concentrations with altitude were generally consistent each year, except at some specific sites (Figure 4). The total SCCP levels increased significantly with altitude on the western and eastern slopes, but the rate of increase on the eastern slopes was smaller than that on the western slopes from 2012 to 2014. On the basis of our previous work, ${ }^{28}$ the turbulent water vapor flux from the Yarlung Tsangpo Valley could increase the mixing rates of the $C_{10}, C_{11}, C_{12}$, and $C_{13}$ homologue groups in the atmosphere above the eastern slopes, causing relatively stable SCCP levels compared with the western slopes. Details regarding the gradient values for the SCCP levels and carbon homologue groups from 2012 to 2015 are presented in Figure $\mathrm{S} 3$ of the SI. The levels of the $\mathrm{C}_{10}$ homologue groups increased faster on the western slopes compared with the eastern slopes, which might be due to the retrograde upwind and the lower molecular weights of the $\mathrm{C}_{10}$ homologue groups, which facilitate transport to higher altitudes.

To estimate the susceptibility of chemicals to mountain coldtrapping, Wania and Westgate proposed the mountain contamination potential (MCP) model to evaluate potential for the mountain cold-trapping based on equilibrium partitioning coefficients between octanol and air $\left(K_{\mathrm{OA}}\right)$ and water and air $\left(K_{\mathrm{WA}}\right) \cdot{ }^{35}$ In their work, MCP was defined as the fraction of the total chemical compounds existing in the two edaphic zones with the highest altitude. On the basis of of MCP calculations (SI), Wania and Westgate proposed that when $\log _{10} K_{\mathrm{OA}}$ and $\log _{10} K_{\mathrm{WA}}$ for the persistent organics satisfied $0<$ $\log _{10} K_{\mathrm{WA}}<6$ and $6<\log _{10} K_{\mathrm{OA}}<12$, the organics possessed mountain cold-trapping ability. In this work, the ranges obtained from calculations of MCP were also applied to estimate the potential ability of the mountain cold-trapping for SCCPs. The SCCPs' $\log _{10} K_{\mathrm{WA}}$ and $\log _{10} K_{\mathrm{OA}}$ values were calculated as 1.33 to 6.89 and 8.49 to 14.29 (Table S4 in the SI), respectively. ${ }^{37}$ According to the range of values for $\log _{10}$ $K_{\mathrm{OA}}$ and $\log _{10} K_{\mathrm{WA}}$, based on the MCP calculations in previous work, some SCCP monomers could be susceptible to mountain cold-trapping to some degree, and this might cause partitioning of SCCPs in colder conditions according to altitude. ${ }^{35,38}$

The gradient value for the concentrations of SCCPs versus altitude might be related to the mountain cold-trapping effect, reflecting an increase of $\sum$ SCCPs along with elevation. As mountain cold-trapping is related to the $\log _{10} K_{\mathrm{OA}}$ and $\log _{10}$ $K_{\mathrm{WA}}$ values of chemical compounds according to the MCP model calculations, the relationship between the gradient and the values of both $\log _{10} K_{\mathrm{OA}}$ and $\log _{10} K_{\mathrm{WA}}$ could reflect the potential for mountain cold-trapping to a certain degree. Correlation analysis found a positive relationship $(P<0.05)$ between the gradient and both $\log _{10} K_{\mathrm{OA}}$ and $\log _{10} K_{\mathrm{WA}}$ for all monomers. A second-order polynomial correlation was 

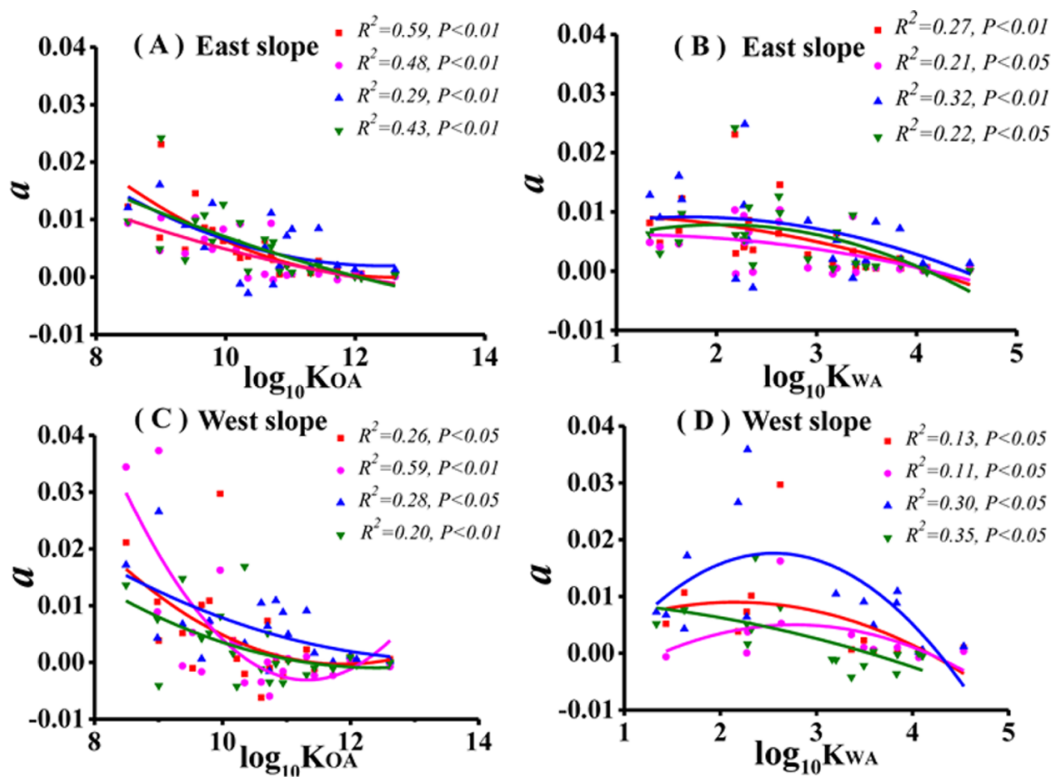

Figure 5. Relationship (Table S2, SI) between the regression slope (a) and the $\log _{10} K_{\mathrm{OW}}$ and $\log _{10} K_{\mathrm{WA}}$ of the monomers from 2012 to 2014 (ש) represented 2012, represented 2013, $\boldsymbol{\Delta}$ represented 2014, and $\boldsymbol{\nabla}$ represented 2015). $\log _{10} K_{\mathrm{OW}}$ and $\log _{10} K_{\mathrm{WA}}$ values fell within the common range of values for all SCCP monomers of SCCPs. The statistical values of $P$ and $R^{2}$ are listed in Table S2 of the SI.
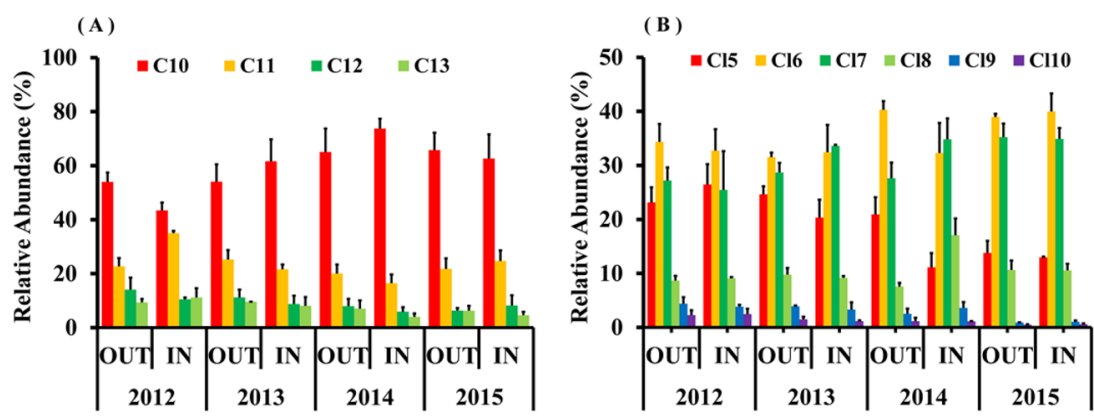

Figure 6. Representative average carbon and chlorinated homologue group abundance profiles for SCCPs inside and outside the forest at Shergyla Mountain from 2012 to 2015.

observed between the gradient and both $\log _{10} K_{\mathrm{OA}}$ and $\log _{10}$ $K_{\mathrm{AW}}$ for monomers from 2012 to 2015 (Figure 5). The fitted polynomial correlation equations are presented in Table S2 of the SI. The gradient reached its maximum value when $\log _{10} K_{\mathrm{OA}}$ was between 8 and 10 and $\log _{10} K_{\mathrm{AW}}$ was between 2 and 3.5 . When $\log _{10} K_{\mathrm{OA}}$ and $\log _{10} K_{\mathrm{AW}}$ were above 10 and 3.5 , respectively, the gradient decreased. In our previous work on the same sampling area, ${ }^{39}$ a similar relationship was found between $\log _{10} K_{\mathrm{OA}}$ and $\log _{10} K_{\mathrm{AW}}$, and the concentration of semivolatile organic chemicals (including $\mathrm{HCHs}$, dichlorodibenzotrichloroethane and its degradation products, endosulfan, heptachloroepoxide, and indicator PCBs) in the air and lichens, indicating that when $\log _{10} K_{\mathrm{OA}}$ and $\log _{10} K_{\mathrm{AW}}$ are within the ranges given above, the mountain cold-trapping ability of these congener groups increased.

Some studies have attributed the increasing trends in air concentrations for some typical POPs with elevation in highaltitude mountain areas to the re-evaporation effect. ${ }^{40}$ The decreasing capacity of high altitude mountains to trap POPs is due to lower amounts of organics in the soil. Additionally, the high $K_{\mathrm{OA}}$ of SCCPs hindered elimination by gas scavenging, which was enhanced by the increasing precipitation in highaltitude mountain areas. ${ }^{38,41,42}$
Potential Forest Filter Effect for SCCPs at Shergyla Mountain. $C_{10}$ and $C_{11}$ homologue groups were the predominant homologue groups both in and outside the forest. The lower chlorinated homologue groups $\left(\mathrm{Cl}_{5-7}\right)$ were the predominant chlorinated homologue groups, and the concentration of $\mathrm{Cl}_{6}$ homologues was relatively high compared with the other chlorinated homologues. Generally, the SCCP concentrations in air outside the forest were higher than that in the forest (3143-4217 $\mathrm{m}$ a.s.l.) during the four-year study period (Figure 6), which is a similar to the results to that found in our previous work on OCPs, PCBs, and PBDEs in the same region. ${ }^{28}$ This result may be due to the forest filter effect, in which the leaves and bark gather POPs from the air and transfer POPs to the soil via forest litter. Other studies have indicated that the forest/clearing ratios for PCBs and some typical organochlorines were between 0.54 and 0.93 at altitudes between 1000 and $1400 \mathrm{~m}$, where broadleaf forests are relatively abundant, but the ratios were higher by a factor of 2 at $1800 \mathrm{~m}$, where conifer forests are dominant. ${ }^{42}$ In this work, the forest/clearing ratios for SCCPs were between 0.52 and 0.93 (Table S3 of the SI) at higher altitudes $(3143-4217 \mathrm{~m}$ ) during the sampling period. This could have been due to the distribution of conifer forests and other vegetation. The average forest/clearing ratios for low molecular weight (300-400), 
medium molecular weight (400-500), and high molecular weight (500-600) monomers were 0.78, 0.97, and 1.20, respectively. Correlation analysis found a positive linear relationship between the molecular weight and forest/clearing ratios (paired-samples $t$-test, $P<0.05$, Figure S4), which indicated that the forest filter effect occurred for these low molecular weight monomers.

Comparison of the SCCP Levels in Air at Shergyla Mountain and Lhasa. The total SCCP concentrations in the atmosphere of Lhasa ranged from 1100 to $14440 \mathrm{pg} / \mathrm{m}^{3}$, approximately 5 orders of magnitude lower than that in Beijing, ${ }^{24}$ whereas they were significantly higher than those at Shergyla Mountain owing to local sources. The ratios of the average concentrations in air between Lhasa and Shergyla Mountain were 10.8, 20.9, 10.1, and 9.6 in the years 2012 to 2015 , respectively, whereas the congener group profiles for the SCCPs at Lhasa were similarly distributed to those at Shergyla Mountain. At Lhasa, the composition of the carbon chains was dominated by the $\mathrm{C}_{10}$ homologue group, followed by the $\mathrm{C}_{11}$ group. The $\mathrm{Cl}_{5}, \mathrm{Cl}_{6}$, and $\mathrm{Cl}_{7}$ groups were the most abundant chlorine homologue groups, with the $\mathrm{Cl}_{6}$ groups accounting for $49.3 \%, 46.4 \%, 48.1 \%$, and $58.8 \%$ of the total SCCPs from 2012 to 2015 , respectively. The lighter molecular weight homologues in the atmosphere were consistent with the composition of air found in inland areas in previous works. ${ }^{24,33}$

Temporal Trends in SCCPs at Shergyla Mountain and Lhasa. Overall, the total SCCP concentrations in air at Shergyla Mountain and Lhasa from 2013 to 2015 exhibited a massive increase compared with 2012 levels (Figure S2 of the SI). The air concentrations showed the highest values in 2014 at Shergyla Mountain while the highest values occurred in 2013 at Lhasa. The proportion of the dominant $\mathrm{Cl}_{6}$ chlorinated homologue groups was stable during the sampling period at both Shergyla Mountain and Lhasa. The percentage of the abundant $\mathrm{C}_{10}$ carbon homologue groups at Lhasa appeared to decline from 2012 to 2015 (73.8\%, 73.6\%, 69.1\% and 59.8\%) although the $\mathrm{C}_{10}$ and $\mathrm{C}_{11}$ congeners still dominated the homologue groups, whereas the opposite trend was observed at Shergyla Mountain. The increasing relative abundance of SCCP homologue groups with longer carbon chains at Lhasa may be due to the combined influences of long-range transport and local emissions sources in this city.

The increasing airborne SCCP concentrations after 2012 are similar to trends seen for total SCCP levels and fluxes along the shores of the Chinese Bohai and Yellow Seas. ${ }^{30}$ This result implies that the continuously release of CPs during the CP production and usage in China since the end of the 1950s has resulted in increasing concentrations of SCCPs in the environment, even in remote areas. However, the decreasing trend observed at Lhasa since 2013 may be due to limited production of potential sources.

Potential Source of the SCCPs Identified by the HYSPLIT Model. To evaluate the possible sources of SCCPs for long-range atmospheric transport, five-day back trajectories, ending at the coordinates of the sampling sites, were calculated based on the Hybrid Single Particle Lagrangian Integrated Trajectory Model (HYSPLIT) from the National Oceanic and Atmospheric Administration of the United States (Figure S5 in the SI). This model showed calculated trajectories at $500 \mathrm{~m}$ above the horizon of Lhasa and at two level heights of 500 and $1000 \mathrm{~m}$ above the horizon at Shergyla Mountain at 6-h time intervals every 3 days during the sampling period (from July 2012 to August 2015). The back trajectory probability maps and the wind field figure (Figure S5A-D) showed that Shergyla Mountain was predominantly influenced by two types of air currents during the sampling period: one from Southwest Asia (Indian monsoon) and the other from South Asia. Considering the similar pattern profiles of SCCPs at Shergyla Mountain and in India and Pakistan, ${ }^{43}$ the potential SCCP sources at Shergyla Mountain are probably related to South Asia. This conclusion also agrees with results from previous works on typical POPs, such as OCPs, PCBs, and PBDEs, in this mountain area. ${ }^{44,45}$

At Lhasa, the SCCPs in the air were also predominantly influenced by the air current from South Asia (Figure S5E-I). Considering the similar potential sources for atmospheric transport from South Asia, and the significantly different concentration trends in the $\mathrm{C}_{10}$ homologue groups, the source of SCCPs at Lhasa might have been related to the SCCP sources from both local urban release and South Asia.

This study explored the levels, the temporal trends, and the environmental behavior of SCCPs at Shergyla Mountain and Lhasa, and revealed the unreported discovery that the $\log _{10} K_{\mathrm{OA}}$ and $\log _{10} K_{\mathrm{WA}}$ values of SCCPs could reflect the potential for mountain cold-trapping. The large amounts and usage of $\mathrm{CP}$ products in China have resulted in increasing concentrations of SCCPs in the air over the Tibetan Plateau. However, as SCCPs were listed under the SC in 2017 to be controlled and eliminated, the Chinese government has begun to regulate $\mathrm{CP}$ products and limit SCCP levels in CP products. In the near future, decreases in the potential adverse effects of SCCPs to the local environment are potentially expected. Further work is warranted to evaluate the possible transport and environmental transformation of SCCPs in this pristine high-altitude area.

\section{ASSOCIATED CONTENT}

\section{Supporting Information}

The Supporting Information is available free of charge on the ACS Publications website at DOI: 10.1021/acs.est.7b03457.

Detailed description of instrumental analysis and additional information for result and discussion. SCCP concentrations (Table S1); fitted polynomial correlation equations (Table S2); the forest/clearing ratios for SCCPs (Table S3); recommended values for logarithmic Henry's law constants for SCCPs (Table S4); XAD absorption curves for total SCCP concentrations (A) and the carbon homologue groups $\mathrm{C}_{10}-\mathrm{C}_{13}$ (B) (Figure $\mathrm{S} 1$ ); total SCCP concentrations (Figure S2); the trends for carbon homologue groups versus altitude (Figure S3); the linear relationship between the molecular weight and the average forest/clearing ratios for total SCCP concentrations (Figure S4); and airshed model for the sampling sites (Figure S5) (PDF)

\section{AUTHOR INFORMATION}

\section{Corresponding Author}

*Tel: 8610-6284-9124; fax: 8610-62849339; e-mail: ywwang@ rcees.ac.cn (Y.W.).

\section{ORCID}

Yawei Wang: 0000-0002-6115-4076

\section{Notes}

The authors declare no competing financial interest. 


\section{ACKNOWLEDGMENTS}

We thank the National Natural Science Foundation of China (21625702, 21337002, and 21621064), the National Basic Research Program of China (2015CB453102), and the Strategic Priority Research Program of the Chinese Academy of Science (XDB14010400) for financial support.

\section{REFERENCES}

(1) Santos, F. J.; Parera, J.; Galceran, M. T. Analysis of polychlorinated $\mathrm{n}$-alkanes in environmental samples. Anal. Bioanal. Chem. 2006, 386 (4), 837-857.

(2) Tomy, G. T.; Stern, G. A.; Muir, D. C. G.; Fisk, A. T.; Cymbalisty, C. D.; Westmore, J. B. Quantifying C10-C13 polychloroalkanes in environmental samples by high-resolution gas chromatography/electron capture negative ion high-resolution mass spectrometry. Anal. Chem. 1997, 69 (14), 2762-2771.

(3) Reth, M.; Ciric, A.; Christensen, G. N.; Heimstad, E. S.; Oehme, M. Short-and medium-chain chlorinated paraffins in biota from the European Arctic differences in homologue group patterns. Sci. Total Environ. 2006, 367 (1), 252-260.

(4) Iozza, S.; Muller, C. E.; Schmid, P.; Bogdal, C.; Oehme, M. Historical profiles of chlorinated paraffins and polychlorinated biphenyls in a dated sediment core from Lake Thun (Switzerland). Environ. Sci. Technol. 2008, 42 (4), 1045-1050.

(5) Houde, M.; Muir, D. C. G.; Tomy, G. T.; Whittle, D. M.; Teixeira, C.; Moore, S. Bioaccumulation and trophic magnification of short- and medium-chain chlorinated paraffins in food webs from Lake Ontario and Lake Michigan. Environ. Sci. Technol. 2008, 42 (10), 3893-3899.

(6) Warnasuriya, G. D.; Elcombe, B. M.; Foster, J. R.; Elcombe, C. R. A Mechanism for the induction of renal tumours in male Fischer 344 rats by short-chain chlorinated paraffins. Arch. Toxicol. 2010, 84 (3), 233-243.

(7) Fisk, A. T.; Tomy, G. T.; Muir, D. C. G. Toxicity of C-10-, C-11-, C-12-, and C-14-polychlorinated alkanes to Japanese medaka (Oryzias latipes) embryos. Environ. Toxicol. Chem. 1999, 18 (12), 2894-2902.

(8) Wang, Y. W.; Fu, J. J.; Jiang, G. B. The research of environmental pollutions and toxic effect of short chain chlorinated paraffins. Environ. Chem. (Chin.) 2009, 28 (1), 1-9.

(9) Thomas, G. O.; Farrar, D.; Braekevelt, E.; Stern, G.; Kalantzi, O. I.; Martin, F. L.; Jones, K. C. Short and medium chain length chlorinated paraffins in UK human milk fat. Environ. Int. 2006, 32 (1), 34-40.

(10) Mackay, D.; Wania, F. Transport of contaminants to the Arctic: partitioning, processes and models. Sci. Total Environ. 1995, 160-161 (2), 25-38

(11) Wania, F.; Mackay, D. Tracking the distribution of persistent organic pollutants. Environ. Sci. Technol. 1996, 30 (9), 390A-396A.

(12) Zencak, Z.; Oehme, M. Recent developments in the analysis of chlorinated paraffins. TrAC, Trends Anal. Chem. 2006, 25 (4), 310317.

(13) Castells, P.; Parera, J.; Santos, F. J.; Galceran, M. T. Occurrence of polychlorinated naphthalenes, polychlorinated biphenyls and shortchain chlorinated paraffins in marine sediments from Barcelona (Spain). Chemosphere 2008, 70 (9), 1552-1562.

(14) Sverko, E.; Tomy, G. T.; Märvin, C. H.; Muir, D. C. G. Improving the quality of environmental measurements on short chain chlorinated paraffins to support global regulatory efforts. Environ. Sci. Technol. 2012, 46 (9), 4697-4698.

(15) Tomy, G. T.; Stern, G. A. Analysis of C14-C17 polychloro-nalkanes in environmental matrixes by accelerated solvent extractionhigh-resolution gas chromatography/electron capture negative ion high-resolution mass spectrometry. Anal. Chem. 1999, 71 (21), 48604865 .

(16) Reth, M.; Zencak, Z.; Oehme, M. New quantification procedure for the analysis of chlorinated paraffins using electron capture negative ionization mass spectrometry. J. Chromatogr. A 2005, 1081 (2), 225231.
(17) Reth, M.; Oehme, M. Limitations of low resolution mass spectrometry in the electron capture negative ionization mode for the analysis of short- and medium-chain chlorinated paraffins. Anal. Bioanal. Chem. 2004, 378 (7), 1741-1747.

(18) Iino, F.; Takasuga, T.; Senthilkumar, K.; Nakamura, N.; Nakanishi, J. Risk assessment of short-chain chlorinated paraffins in Japan based on the first market basket study and species sensitivity distributions. Environ. Sci. Technol. 2005, 39 (3), 859-866.

(19) Borgen, A. R.; Schlabach, M.; Kallenbirn, R.; Christensen, G.; Skotvold, T. Polychlorinated alkanes in ambient air from Bear Island. Organohalogen compd. 2002, 47, 303-306.

(20) Barber, J. L.; Sweetman, A. J.; Thomas, G. O.; Braekevelt, E.; Stern, G. A.; Jones, K. C. Spatial and temporal variability in air concentrations of short-chain (C10-C13) and medium-chain (C14C17) chlorinated n-alkanes measured in the UK atmosphere. Environ. Sci. Technol. 2005, 39 (12), 4407-4415.

(21) Ma, X. D.; Zhang, H. J.; Zhou, H. Q.; Na, G. S.; Wang, Z.; Chen, C.; Chen, J. W.; Chen, J. P. Occurrence and gas/particle partitioning of short- and medium-chain chlorinated paraffins in the atmosphere of Fildes Peninsula of Antarctica. Atmos. Environ. 2014, 90 (1), 10-15.

(22) Li, H. J.; Fu, J. J.; Zhang, A. Q.; Zhang, Q. H.; Wang, Y. W. Occurrence, bioaccumulation and long-range transport of short chain chlorinated paraffins on the Fildes Peninsula and King George Island, Antarctica. Environ. Int. 2016, 94, 408-414.

(23) Li, Q. L.; Li, J.; Wang, Y.; Pan, X. H.; Xu, Y.; Zhang, G.; Luo, C. L.; Kobara, Y.; Nam, J. J.; Jones, K. C. Atmospheric short-chain chlorinated paraffins in China, Japan, and South Korea. Environ. Sci. Technol. 2012, 46 (21), 11948-11954.

(24) Wang, T.; Han, S. L.; Yuan, B.; Zeng, L. X.; Li, Y. M.; Wang, Y. W.; Jiang, G. B. Summer-winter concentrations and gas-particle partitioning of short chain chlorinated paraffins in the atmosphere of an urban setting. Environ. Pollut. 2012, 171, 38-45.

(25) Li, J.; Lin, T.; Qi, S. H.; Zhang, G.; Liu, X.; Li, K. Evidence of local emission of organochlorine pesticides in the Tibetan plateau. Atmos. Environ. 2008, 42 (32), 7397-7404.

(26) Choi, S. D.; Baek, S. Y.; Chang, Y. S.; Wania, F.; Ikonomou, M. G.; Yoon, Y. J.; Park, B. K.; Hong, S. Passive air sampling of polychlorinated biphenyls and organochlorine pesticides at the Korean Arctic and Antarctic research stations: Implications for long-range transport and local pollution. Environ. Sci. Technol. 2008, 42 (19), $7125-7131$

(27) Wania, F.; Shen, L.; Lei, Y.; Teixeira, C.; Muir, D. C. G. Development and calibration of a resin-based passive sampling system for monitoring persistent organic pollutants in the atmosphere. Environ. Sci. Technol. 2003, 37 (7), 1352-1359.

(28) Zhu, N. L.; Schramm, K. W.; Wang, T.; Henkelmann, B.; Zheng, X. Y.; Fu, J. J.; Gao, Y.; Wang, Y. W.; Jiang, G. B. Environmental fate and behavior of persistent organic pollutants in Shergyla Mountain, southeast of the Tibetan Plateau of China. Environ. Pollut. 2014, 191, $166-174$.

(29) Yuan, B.; Wang, Y. W.; Fu, J. J.; Jiang, G. B.; Zhang, Q. An analytical method for chlorinated paraffins and their determination in soil samples. Chin. Sci. Bull. 2010, 55 (22), 2396-2402.

(30) Zeng, L. X.; Chen, R.; Zhao, Z. S.; Wang, T.; Gao, Y.; Li, A.; Wang, Y. W.; Jiang, G. B.; Sun, L. Spatial distributions and deposition chronology of short chain chlorinated paraffins in marine sediments across the Chinese Bohai and Yellow Seas. Environ. Sci. Technol. 2013, 47 (20), 11449-11456.

(31) Zeng, L. X.; Wang, T.; Ruan, T.; Liu, Q.; Wang, Y. W.; Jiang, G. B. Levels and distribution patterns of short chain chlorinated paraffins in sewage sludge of wastewater treatment plants in China. Environ. Pollut. 2012, 160, 88-94.

(32) Liu, W. J.; Chen, D. Z.; Liu, X. D.; Zheng, X. Y.; Yang, W.; Westgate, J. N.; Wania, F. Transport of semivolatile organic compounds to the Tibetan plateau: spatial and temporal variation in air concentrations in mountainous Western Sichuan, China. Environ. Sci. Technol. 2010, 44 (5), 1559-1565.

(33) Wang, Y.; Li, J.; Cheng, Z.; Li, Q. L.; Pan, X. H.; Zhang, R. J.; Liu, D.; Luo, C. L.; Liu, X.; Katsoyiannis, A.; Zhang, J. Short-and 
medium-chain chlorinated paraffins in air and soil of subtropical terrestrial environment in the Pearl River Delta, South China: Distribution, composition, atmospheric deposition fluxes, and environmental fate. Environ. Sci. Technol. 2013, 47 (6), 2679-2687.

(34) Zeng, L.; Wang, T.; Wang, P.; Liu, Q.; Han, S. L.; Yuan, B.; Zhu, N. L.; Wang, Y. W.; Jiang, G. B. Distribution and trophic transfer of short-chain chlorinated paraffins in an aquatic ecosystem receiving effluents from a sewage treatment plant. Environ. Sci. Technol. 2011, 45 (13), 5529-5535.

(35) Wania, F.; Westgate, J. N. On the mechanism of mountain coldtrapping of organic chemicals. Environ. Sci. Technol. 2008, 42 (24), 9092-9098.

(36) Grimalt, J. O.; Fernandez, P.; Berdie, L.; Vilanova, R. M.; Catalan, J.; Psenner, R.; Hofer, R.; Appleby, P. G.; Rosseland, B. O.; Lien, F.; Massabuau, J. C.; Battarbee, R. W. Selective Trapping of Organochlorine Compounds in Mountain Lakes of Temperate Areas. Environ. Sci. Technol. 2001, 35 (13), 2690-2697.

(37) Glüge, J.; Bogdal, C.; Scheringer, M.; Buser, A. M.; Hungerbühler, K. Calculation of physicochemical properties for short- and medium-chain chlorinated paraffins. J. Phys. Chem. Ref. Data 2013, 42 (2), 023103-023103-12.

(38) Davidson, D. A.; Wilkinson, A. C.; Blais, J. M.; Kimpe, L. E.; McDonald, K. M.; Schindler, D.W. Orographic cold-trapping of persistent organic pollutants by vegetation in mountains of western Canada. Environ. Sci. Technol. 2003, 37 (2), 209-215.

(39) Zhu, N. L.; Schramm, K. W.; Wang, T.; Henkelmann, B.; Fu, J. J.; Gao, Y.; Wang, Y. W.; Jiang, G. B. Lichen, moss and soil in resolving the occurrence of semi-volatile organic compounds on the southeastern Tibetan Plateau, China. Sci. Total Environ. 2015, 518-519, $328-336$.

(40) Loewen, M.; Wania, F.; Wang, F. Y.; Tomy, G. Altitudinal Transect of Atmospheric and Aqueous Fluorinated Organic Compounds in Western Canada. Environ. Sci. Technol. 2008, 42 (7), 2374.

(41) Wania, F. On the origin of elevated levels of persistent chemicals in the environment. Environ. Sci. Pollut. Res. 1999, 6 (1), 11-19.

(42) Jaward, F. M.; Di Guardo, A.; Nizzetto, L.; Cassani, C.; Raffaele, F.; Ferretti, R; Jones, K. C. PCBs and selected organochlorine compounds in Italian mountain air: the influence of altitude and forest ecosystem type. Environ. Sci. Technol. 2005, 39 (10), 3455-3463.

(43) Chaemfa, C.; Xu, Y.; Li, J.; Chakraborty, P.; Syed, J. H.; Malik, R. N.; Wang, Y.; Tian, C.; Zhang, G.; Jones, K. C. Screening of atmospheric short-and medium-chain chlorinated paraffins in India and Pakistan using polyurethane foam based passive air sampler. Environ. Sci. Technol. 2014, 48 (9), 4799-4808.

(44) Wang, X. P.; Gong, P.; Yao, T. D.; Jones, K. C. Passive air sampling of organochlorine pesticides, polychlorinated biphenyls, and polybrominated diphenyl ethers across the Tibetan Plateau. Environ. Sci. Technol. 2010, 44 (8), 2988-2993.

(45) Sheng, J. J.; Wang, X. P.; Gong, P.; Joswiak, D. R.; Tian, L. D.; Yao, T. D.; Jones, K. C. Monsoon-driven transport of organochlorine pesticides and polychlorinated biphenyls to the Tibetan Plateau: three year atmospheric monitoring study. Environ. Sci. Technol. 2013, 47 (7), 3199-3208. 